\title{
Cryofibrinogenaemia and acute gangrene in systemic sclerosis
}

\author{
M.C. Barrett ${ }^{1}$, J.S. Prendiville ${ }^{2}$, B.J. Pardy ${ }^{3}$ and J.J. Cream ${ }^{2}$ \\ Departments of ${ }^{1}$ Histopathology, ${ }^{2}$ Dermatology and ${ }^{3}$ Surgery, Charing Cross and Westminster Medical School, \\ Charing Cross Hospital, Fulham Palace Road, London W6 8RF, UK.
}

\begin{abstract}
Summary: A 49 year old man with systemic sclerosis developed ischaemia of his extremities with massive peripheral gangrene. High levels of circulating cryofibrinogen were detected in the plasma and the significance of these findings is discussed.
\end{abstract}

\section{Introduction}

Cryofibrinogen is a complex of fibrin, fibrinogen and fibronectin which forms in plasma (Stathakis et al., 1978). Cryofibrinogenaemia may be associated with thrombosis and purpura and it has been reported in malignancy, acute infections and systemic lupus erythematosus (Smith \& Arkin, 1972), yet is rarely sought in routine laboratories. The relationship between circulating cryofibrinogen and the pathogenesis of such disorders is still unclear.

We report a patient with systemic sclerosis and cryofibrinogenaemia who presented with massive peripheral gangrene.

\section{Case report}

A 49 year old retired male H.M. Customs official was transferred to Charing Cross Hospital in January 1986. Eleven years previously, systemic sclerosis had been diagnosed. During this time he had had recurrent pneumothoraces and his chest X-ray had been reported as showing honeycomb lung, fibrosis and large airfilled, cystic spaces. Bilateral pleurodesis was carried out in 1981. Two weeks before admission and during a particularly cold spell, he rapidly developed ischaemia of all his extremities, progressing to digital gangrene. These changes were extraordinarily severe and without obvious cause.

On examination, he was confused and, in addition to scleroderma of the face, hands and knees, he had gangrene of the finger tips. There was also gangrene of the toes extending on to the feet over which there was a mottled cyanosis. There were necrotic, sloughing areas and bullae over the dorsal aspects of both feet. His blood pressure was $150 / 90 \mathrm{mmHg}$. All peripheral pulses were full and easily palpable. His core tem-

Correspondence: M.C. Barrett B.Sc., Ph.D.

Accepted: 12 May 1986 perature was between $35^{\circ} \mathrm{C}$ and $36^{\circ} \mathrm{C}$ and remained so during the first week.

Other investigations revealed an erythrocyte sedimentation rate of $27 \mathrm{~mm}$ in the first hour, a haemoglobin of $12.3 \mathrm{~g} / \mathrm{dl}$, white cell count $18.6 \times 10^{9} / 1$ and platelet count $240 \times 10^{9} / 1$. No abnormality was detected in his coagulation screen. His plasma viscosity was normal. No cold agglutinins or cryoglobulins were detected but the plasma cryofibrinogen was $435 \mathrm{mg} / \mathrm{l}($ normal $<40$ ). His blood urea was $5.2 \mathrm{mmol} / \mathrm{l}$, serum creatinine $88 \mu \mathrm{mol} / \mathrm{l}$.

Despite subcutaneous heparin, intravenous Dextran 40 and prostaglandin E1, much of the ischaemia proved to be irreversible and he died.

\section{Discussion}

The cutaneous features of systemic sclerosis had been present in this patient for several years. In addition, he had honeycomb lung and large air-filled cystic spaces and had had recurrent pneumothoraces. These pulmonary findings are unusual in systemic sclerosis but have been described previously by Israel \& Harley (1956).

The sudden development of rapidly progressive peripheral ischaemia with gangrene in systemic sclerosis is unusual. Notable was our patient's high level of cryofibrinogen which has not been observed before in proven unequivocal systemic sclerosis, although cryofibrinogenaemia has been reported in Raynaud's phenomenon. It is not possible in this case to say whether the cryofibrinogenaemia preceded the gangrene. However, Waxman \& Dove (1969) showed that high levels of cryofibrinogen can give rise to skin injury. It is of interest that our patient was hypothermic and developed his gangrene during a very cold spell.

The finding of cryofibrinogenaemia has therapeutic 
implications and should not be overlooked in patients with cold-related skin damage. Severe symptomatic cryofibrinogenaemia has been treated with oral Varidase (streptokinase-streptodornase) alone (Rach-

\section{References}

COPEMAN, P.W.M. (1979). Cryofibrinogenaemia and skin ulcers: treatment with plasmapheresis. British Journal of Dermatology, 101 (Suppl. 17), 57.

ISRAEL, M.S. \& HARLEY, B.J.S. (1956). Spontaneous pneumothorax in scleroderma. Thorax, 11, 113.

RACHMILEWITZ, E.A., SACKS, M.I. \& ZLOTNICK, A. (1970). Essential cryofibrinogenaemia. Clinical, pathological and immunological studies. Israel Journal of Medical Science, 6, 32.

SMITH, S.B. \& ARKIN, C. (1972). Cryofibrinogenaemia: incidence, clinical correlations, and a review of the literature. American Journal of Clinical Pathology, 58, 524. milewitz et al., 1970) and in combination with plasmapheresis (Copeman, 1979). The patient should also be kept in a warm environment.

STATHAKIS, N.E., MOSESSON, M.W., CHEN, A.B. \& GALANAKIS, D.K. (1978). Cryoprecipitation of fibrin-fibrinogen complexes induced by the cold-insoluble globulin of plasma. Blood, 6, 1211.

WAXMAN, S. \& DOVE, J.T. (1969). Cryofibrinogenaemia aggravated during hypothermia. New England Journal of Medicine, 281, 1291. 